\title{
Optical and Electronic Properties of Fluorene-Based Copolymers and Their Sensory Applications
}

\author{
Vüsala Ibrahimova, ${ }^{1,2}$ Meliha Eda Kocak, ${ }^{1}$ Ahmet M. Önal, ${ }^{3}$ Dönüs Tuncel ${ }^{1,2}$ \\ ${ }^{1}$ Department of Chemistry, Bilkent University, 06800 Ankara, Turkey \\ ${ }^{2}$ UNAM-National Nanotechnology Research Center, Bilkent University, 06800 Ankara, Turkey \\ ${ }^{3}$ Department of Chemistry, Middle East Technical University, 06800 Ankara, Turkey \\ Correspondence to: A. M. Önal (E-mail: aonal@metu.edu.tr) or D. Tuncel (E-mail: dtuncel@fen.bilkent.edu.tr)
}

Received 16 October 2012; accepted 25 October 2012; published online 26 November 2012

DOI: $10.1002 /$ pola.26454

ABSTRACT: A series of novel, fluorene-based conjugated copolymers, poly[(9,9-bis\{propenyl\}-9H-fluorene)-co-(9,9-dihexyl$9 \mathrm{H}$-fluorene)] (P1), poly[(9,9-bis\{carboxymethylsulfonyl-propyl\}fluorenyl-2,7-diyl)-co-(9,9-dihexyl-9H-fluorene)] (P2) and poly[(9,9dihexylfluorene)-co-alt-(9,9-bis-(6-azidohexyl)fluorene)] (P3), are synthesized by Suzuki coupling reactions and their electrochemical properties, in the form of films, are investigated using cyclic voltammetry. The results reveal that the polymer films exhibit electrochromic properties with a pseudo-reversible redox behavior; transparent in the neutral state and dark violet in the oxidized state. Among the three polymers, P2 possesses the shortest response time and the highest coloration efficiency value. These polymers emit blue light with a band gap value of around $2.9 \mathrm{eV}$ and have high fluorescent quantum yields. Their metal ion sensory abilities are also investigated by titrating them with a number of different transition metal ions; all of these polymers exhibit a higher selectivity toward $\mathrm{Fe}^{3+}$ ions than the other ions tested with Stern-Volmer constants of $4.41 \times 10^{6} \mathrm{M}^{-1}, 3.28 \times 10^{7} \mathrm{M}^{-1}$, $1.25 \times 10^{6} \mathrm{M}^{-1}$, and $6.56 \times 10^{6} \mathrm{M}^{-1}$ for $\mathbf{P 1}, \mathbf{P 2}$, water soluble version of P2 (P2S) and P3, respectively. (C) 2012 Wiley Periodicals, Inc. J. Polym. Sci., Part A: Polym. Chem. 2013, 51, 815-823

KEYWORDS: fluorene-based polymers; electrochromism; ion sensing; fluorescence
INTRODUCTION Conjugated polymers with tailored properties are of still great attention due to their wide range of applications including organic light emitting diodes, ${ }^{1-3}$ solar cells, ${ }^{4,5}$ and electrochromic devices. ${ }^{6,7}$ Moreover, the use of light emitting conjugated polymers as chemosensors to detect analytes is rather appealing owing to the ability of the conjugated backbone to amplify the signal through the wiring effect. ${ }^{8-10}$

Among a great number of conjugated polymers with different emissive colors, polyfluorenes (PFs) are promising materials for optoelectronic devices due to their high thermal and chemical stability together with high photoluminescence efficiency and good photostability. ${ }^{11-13}$ A further advantage of utilizing PFs is that their properties can be tuned by structural design, either via substitution of the C-9 position of fluorene by suitable substituents to enhance solubility ${ }^{14-16}$ or copolymerization of fluorene with various aryl partners to tune their electronic properties. ${ }^{17-25}$

Furthermore, the use of fluorene-based conjugated polymers as a fluorescent chemosensor is becoming highly attractive because of a number of reasons. First, they possess high florescent quantum yields; second, suitable ligands which have ability to coordinate with the desired ions can be incorpo- rated to the fluorene backbone easily. These features make them suitable in sensing biologically and environmentally important metal ions selectively and at low detection limits. $^{26-32}$ For instance, C-9 position of fluorene was functionalized with various groups such as phosphonates, sulfonates, and dendronized amino acids and subsequently these monomers were polymerized using Suzuki Coupling reactions to obtain water soluble blue emitting polymers which can be utilized as chemosensors. ${ }^{29-32}$ It was shown that the PF with having phosphonates ${ }^{30}$ and sulfonates ${ }^{31}$ groups detects $\mathrm{Fe}^{+3}$ ions in water with the Stern-Volmer constants $\left(K_{\text {sv }}\right)$ of 1.50 $\times 10^{6} \mathrm{M}^{-1}$ and $1.98 \times 10^{6} \mathrm{M}^{-1}$, respectively, whereas dendronized amino acid functionalized polyflurone ${ }^{32}$ was found to be selective toward $\mathrm{Hg}^{2+}$ ions with $K_{\mathrm{sv}}$ of $1.33 \times$ $10^{6} \mathrm{M}^{-1}$. The fluorescent quenching of the aforementioned polymers by those metal ions have been attributed to a combination of factors such as electron transfer, delocalization of excitons, and energy migration along the polymer chain. ${ }^{30-32}$

Herein, we report on the synthesis and characterization of a series of new spray processable fluorescent copolymers; poly[(9,9-bis\{propenyl\}-9H-fluorene)-co-(9,9-dihexyl-9H-fluorene)] (P1), poly[(9,9-bis\{carboxymethylsulfonyl-propyl\}fluorenyl-2,7-diyl)-co-(9,9-dihexyl-9H-fluorene) (P2), and

Additional Supporting Information may be found in the online version of this article.

(c) 2012 Wiley Periodicals, Inc.

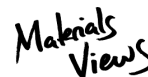




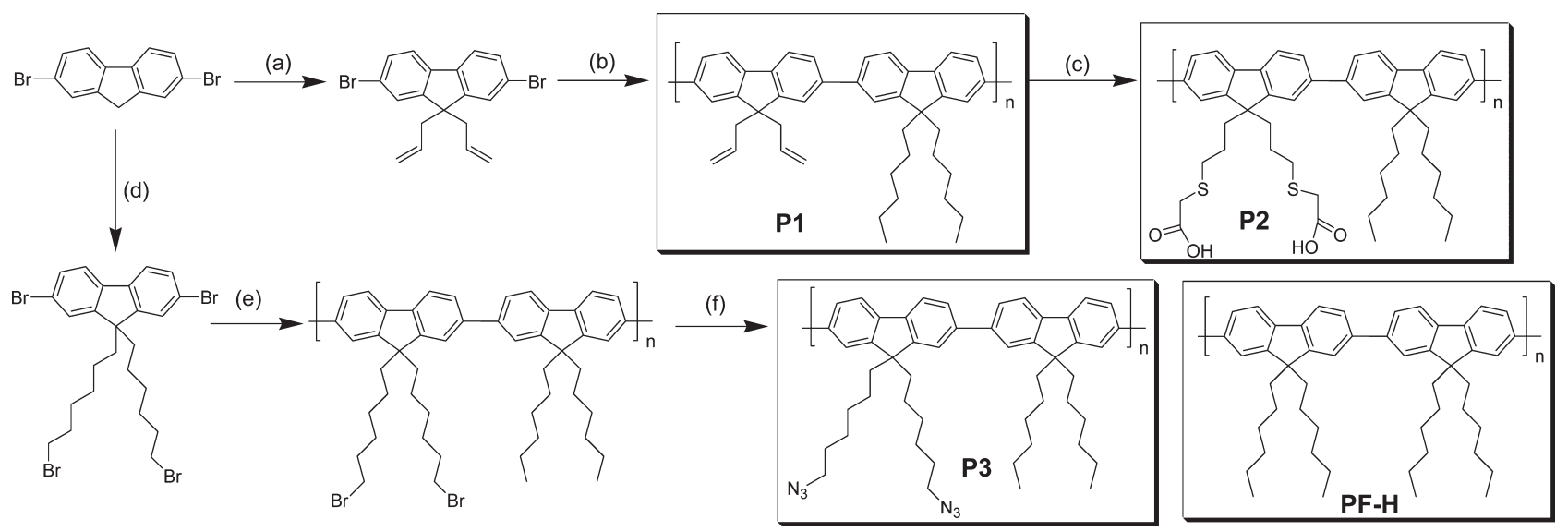

SCHEME 1 The structures of the polymers (P1-P3 and PF-H) used in this study and the synthesis of the polymers P1-P3. (a) Allylbromide, $50 \% \mathrm{NaOH}$ aq.solution (w/w), DMSO, TBAB, $2 \mathrm{~h}, 89 \%$; (b) 9,9-dihexylfluorene-2,7-bis(trimethyleneborate), $\mathrm{K}_{2} \mathrm{CO}_{3},(\mathrm{Pd}$ $\left.\left(\mathrm{PPh}_{3}\right)_{4}\right)$, THF/ $\mathrm{H}_{2} \mathrm{O} /$ Toluene, TBAB, 80-90 ${ }^{\circ} \mathrm{C}, 48 \mathrm{~h}, 60 \%$; (c) Thioglycolic acid, $\mathrm{CHCl}_{3}, 25{ }^{\circ} \mathrm{C}, 24 \mathrm{~h}, 90 \%$; (d) 1,6-dibromohexane, 50\% $\mathrm{NaOH}$ aq.solution (w/w), DMSO, TBAB, $2 \mathrm{~h}, 60 \%$; (e) 9,9-dihexylfluorene-2,7-bis(trimethyleneborate), $\mathrm{K}_{2} \mathrm{CO}_{3},\left(\mathrm{Pd}\left(\mathrm{PPh}_{3}\right)_{4}\right), \mathrm{THF} / \mathrm{H}_{2} \mathrm{O} /$ Toluene, TBAB, $80-90{ }^{\circ} \mathrm{C}, 48 \mathrm{~h}, 56 \%$; (f) $\mathrm{NaN}_{3}, \mathrm{DMF}, 70{ }^{\circ} \mathrm{C}, 24 \mathrm{~h}, 85 \%$.

poly[(9,9-dihexylfluorene)-co-alt-(9,9-bis-(6-azidohexyl)fluorine)] (P3) (Scheme 1). Electro-optical and electrochromic properties of these new copolymers were investigated using cyclic voltammetry (CV) and in situ spectroelectrochemical techniques. Furthermore, the fluorescence properties of polymers were investigated in tetrahydrofuran (THF). Their metal ion sensory abilities were also investigated and the results were compared with poly(9,9-dihexyl-9H-fluorene) (PF-H) (Scheme 1) carrying no functional groups to understand the extent of the functional group effect on the fluorescent sensing.

\section{EXPERIMENTAL}

\section{Materials}

All chemicals including 2,7-dibromofluorene, 9,9-dihexylfluorene-2,7-bis(trimethyleneborate), phase transfer catalyst tetrabutylammoniumbromide and tetrakis(triphenylphosphine)palladium, were purchased from Aldrich.

\section{Synthesis of 2,7-Dibromo-9,9-bis-(propenyl)-} 9H-fluorene (M)

2,7-Dibromofluorene (3.00 g, $9.25 \mathrm{mmol})$ and tetrabutylammonium bromide (TBAB) (0.600 g, $1.85 \mathrm{mmol})$ were dried under vacuum for $30 \mathrm{~min}$. Degassed dimethyl sulfoxide (DMSO) (15 mL), 50\% (w/w) NaOH (15 mL), allylbromide $(16 \mathrm{~mL}, 90 \mathrm{mmol})$ were added into the mixture, respectively, and stirred under argon gas for $2 \mathrm{~h}$ at room temperature. After $2 \mathrm{~h}, t$-butyl methyl ether $(125 \mathrm{~mL})$ and deionized water $(50 \mathrm{~mL})$ were added into the mixture and stirred $15 \mathrm{~min}$. Organic layer was separated and subsequently washed with deionized water $(50 \mathrm{~mL}), 2 \mathrm{~N} \mathrm{HCl}(50 \mathrm{~mL})$, brine solution $(50 \mathrm{~mL})$, and deionized water $(50 \mathrm{~mL})$, respectively. After extraction, $t$-butyl methyl ether was evaporated by rotary evaporator to obtain a solid residue which was purified using a silica-packed column and cyclohexane as an eluent. The solid was further purified by dissolving in $\mathrm{CHCl}_{3}$, precip- itating into cold methanol. Colorless crystals were collected and dried under vacuum (3.3 g, 89\%).

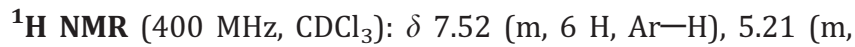
$\left.2 \mathrm{H},-\mathrm{CH}=\mathrm{CH}_{2}\right), 4.89\left(\mathrm{~m}, 4 \mathrm{H},-\mathrm{CH}=\mathrm{CH}_{2}\right), 2.68(\mathrm{t}, 4 \mathrm{H}$, $\left.-\mathrm{CH}_{2}-\overline{{ }^{3} \mathrm{~J}}=4 \mathrm{~Hz}\right) \cdot{ }^{13} \mathrm{C}-\mathrm{NMR}\left(100 \mathrm{MHz}^{-} \mathrm{CDCl}_{3}\right): \delta 42,46$, $114,122,129,130,132,135,138$, and 144.

Synthesis of Poly[(9,9-bis\{propenyl\}-9H-fluorene)-co-(9,9dihexyl-9H-fluorene)] (P1)

2,7-Dibromo-9,9-bis-(propenyl)-9H-fluorene (1.00 g, 3.00 mmol), 9,9-dihexylfluorene-2,7-bis(trimethyleneborate) (0.49 g, $3.00 \mathrm{mmol}$ ) and $\mathrm{K}_{2} \mathrm{CO}_{3}(4.09 \mathrm{~g}, 3.00 \mathrm{mmol})$ were dried under vacuum. First the degassed solvents, THF $(10 \mathrm{~mL})$, water $(10 \mathrm{~mL})$, and toluene $(10 \mathrm{~mL})$ were added under Argon gas and then, catalyst tetrakis (triphenylphosphine) palladium $\left(\mathrm{Pd}\left(\mathrm{PPh}_{3}\right)_{4}\right)$ was added quickly. After $3 \mathrm{~h}$ stirring of the mixture under argon at $80-90{ }^{\circ} \mathrm{C}$, the phase transfer catalyst, tetra-n-butylammonium bromide (TBAB) was added. The stirring was continued for another $48 \mathrm{~h}$ at $80-90{ }^{\circ} \mathrm{C}$ to complete the polymerization reaction. The mixture was evaporated under vacuum to obtain a solid residue, which was suspended in water; the water insoluble particles were collected by suction and dissolved in THF $(20 \mathrm{~mL})$ and the solution was precipitated into cold methanol $(200 \mathrm{~mL})$. The precipitates were collected by suction and dried under vacuum for $5 \mathrm{~h}$ at rt. $(0.900 \mathrm{~g}, 60 \%)$.

${ }^{1} \mathbf{H}$ NMR (400 MHz, $\left.\mathrm{CDCl}_{3}, 25^{\circ} \mathrm{C}\right): \delta 7.85(\mathrm{~m}, 8 \mathrm{H}, \mathrm{ArH}), 5.54$ $\left(\mathrm{m}, 2 \mathrm{H},-\mathrm{CH}=\mathrm{CH}_{2}\right), 5.02\left(\mathrm{t}, 4 \mathrm{H},-\mathrm{CH}=\mathrm{CH}_{2}\right), 2.89(\mathrm{~m}, 4 \mathrm{H}$, $\left.-\mathrm{CH}_{2} \mathrm{CH}=\mathrm{CH}_{2}\right), 1.54\left(\mathrm{~m}, 4 \mathrm{H},-\mathrm{CH}_{2}-\overline{-}\right) 1.15 \quad(\mathrm{~m}, 4 \mathrm{H}$, $-\mathrm{CH}_{2}-$ ), and $0.81\left(\mathrm{~m}, 6 \mathrm{H},-\mathrm{CH}_{3}\right.$ ) (see NMR spectrum in Supporting Information Fig. S1).

IR [KBr, pellet, $\left.v_{\max }\left(\mathrm{cm}^{-1}\right)\right]: 3023(-\mathrm{CH}, \mathrm{w}), 2928(-\mathrm{CH}, \mathrm{s})$, $919(\mathrm{C}=\mathrm{C}-\mathrm{w})$.

Gel permeation chromatography (GPC): $M_{\mathrm{n}}=4.01 \times 10^{3}$ $\mathrm{g} \mathrm{mol}^{-1}, M_{\mathrm{w}}=9.02 \times 10^{3} \mathrm{~g} \mathrm{~mol}^{-1}$ (THF as a solvent and polystyrene as standard). Anal. calcd for $\mathrm{C}_{239} \mathrm{H}_{256} \mathrm{Br}_{2}$ (Exact 
Mass: 3283.8399): C, 87.29; H, 7.85; $\mathrm{Br}, 4.86$. Found: C, 87.37; H, 7.97.

Synthesis of Poly[(9,9-bis\{carboxymethylsulfonylpropylffluorenyl-2,7-diyl)-co-(9,9-dihexyl-9H-fluorene) (P2)

P2 was synthesized through thiol-ene click chemistry. Poly[(9,9-bis\{propenyl\}-9H-fluorene)-co-(9,9-dihexyl-9H-fluorene)] (200 $\mathrm{mg}, 0.374 \mathrm{mmol}$ ) was dissolved in chloroform $(5 \mathrm{~mL})$ and treated with thioglycolic acid $(0.163 \mathrm{~mL}, 1.87$ $\mathrm{mmol}$ ). The mixture was stirred under argon at $\mathrm{rt}$ for $24 \mathrm{~h}$. Chloroform was evaporated off and the remaining residue was dissolved in THF $(5 \mathrm{~mL})$ and the solution was precipitated into water $(50 \mathrm{~mL})$. Yellow precipitate was collected by centrifugation and the precipitation process was repeated twice to remove the excess thioglycolic acid. The yellow precipitate was dried under vacuum for $5 \mathrm{~h}$ at rt. $(180 \mathrm{mg}$, 90\%). IR (KBr, pellet, $v_{\max }\left(\mathrm{cm}^{-1}\right)$ ): $3036(-\mathrm{CH}, \mathrm{w}), 2928$ $(-\mathrm{CH}, \mathrm{s}), 1458(\mathrm{C}=\mathrm{C}-, \mathrm{w}), 1705(\mathrm{C}=0, \mathrm{~s}) . \mathbf{G P C}: M_{\mathrm{n}}=9.88$ $\times 10^{3} \mathrm{~g} \mathrm{~mol}^{-1}, M_{\mathrm{w}}=12.9 \times 10^{4} \mathrm{~g} \mathrm{~mol}^{-1}(\mathrm{THF}$ as a solvent and polystyrene as standard). Anal. calcd for $\mathrm{C}_{403} \mathrm{H}_{464} \mathrm{Br}_{2} \mathrm{O}_{32} \mathrm{~S}_{16}$ (Exact Mass: 6484.8579): C, 74.55; $\mathrm{H}$, 7.20; Br, 2.46; 0, 7.89; S, 7.90. Found: C, 74.59; H, 7.27; S, 7.68 .

Synthesis of Poly[(9,9-dihexylfluorene)co-alt-(9,9-bis-(6-azidohexyl) fluorene)] (P3)

P3 was synthesized following the literature procedure. ${ }^{33-34}$

IR $\left(\mathrm{KBr}, \mathrm{cm}^{-1}\right)$ : 3065(CH-), 2935 (CH-), $2859(\mathrm{CH}-), 2100$ $\left(-\mathrm{N}_{3}\right), 1613(\mathrm{C}=\mathrm{C}-)$, and $1571(\mathrm{C}=\mathrm{C})$.

${ }^{1}$ H NMR $\left(400 \mathrm{MHz}, \mathrm{CDCl}_{3}\right): \delta 7.78(\mathrm{~m}, 12 \mathrm{H}), 3.17(\mathrm{~m}, 4 \mathrm{H})$, $1.95(\mathrm{~m}, 4 \mathrm{H}), 1.7(\mathrm{~m}, 4 \mathrm{H}), 1.20(\mathrm{~m}, 8 \mathrm{H})$, and $0.65(\mathrm{~m}, 4 \mathrm{H}, \mathrm{f})$.

GPC: $M_{\mathrm{n}}=3.61 \times 10^{3} \mathrm{~g} \mathrm{~mol}^{-1}, M_{\mathrm{w}}=2.04 \times 10^{4} \mathrm{~g} \mathrm{~mol}^{-1}$ (THF as a solvent and polystyrene as standard).

\section{Preparation of Polymers and Metal Ion Solutions, and} the Fluorescent Titrations

Polymers P1, P2, and P3 (0.75, 0.92, and $0.97 \mathrm{mg}$, respectively) were dissolved in THF (250 $\mathrm{mL})$ to prepare the stock solutions with $5 \mu \mathrm{M}$ concentrations (respect to per repeat unit). P2S (9.7 $\mathrm{mg}$ ) was dissolved in water $(250 \mathrm{~mL})$ to prepare its stock solution with a concentration of $50 \mu \mathrm{M}$. Metal ions stock solutions were prepared by dissolving $\mathrm{Fe}\left(\mathrm{NO}_{3}\right)_{3} \cdot 9 \mathrm{H}_{2} \mathrm{O}, \mathrm{Cu}\left(\mathrm{NO}_{3}\right)_{2} \cdot 3 \mathrm{H}_{2} \mathrm{O}$, $\mathrm{Ni}\left(\mathrm{NO}_{3}\right)_{2} \cdot 6 \mathrm{H}_{2} \mathrm{O}, \mathrm{Zn}\left(\mathrm{NO}_{3}\right)_{2} \cdot 6 \mathrm{H}_{2} \mathrm{O}, \mathrm{AgNO}_{3}, \mathrm{Hg}\left(\mathrm{NO}_{3}\right)_{2}, \mathrm{~Pb}\left(\mathrm{NO}_{3}\right)_{2}$, and $\mathrm{Cd}\left(\mathrm{NO}_{3}\right)_{2} \cdot 4 \mathrm{H}_{2} \mathrm{O}, \mathrm{Fe}\left(\mathrm{NO}_{3}\right)_{2} \cdot 6 \mathrm{H}_{2} \mathrm{O}(2.02,1.21,1.45,1.49$, $0.85,1.62,1.66,1.54$, and $1.44 \mathrm{mg}$, respectively) in $5 \mathrm{~mL}$ of water to get the concentration of $0.001 \mathrm{M}$. For the fluorescent titration experiments, $3 \mathrm{~mL}$ stock solution of polymers were taken to the UV cuvette followed by successive additions of 15 $\mu \mathrm{L}$ of metal ion stock solutions. Fluorescence spectrum were taken after each addition.

\section{Instrumentation}

NMR spectra were recorded on a Bruker NMR Spectrometer (DPX-400) in deuterated chloroform and fluorescence measurements were recorded on a Varian Cary Eclipse Fluores-

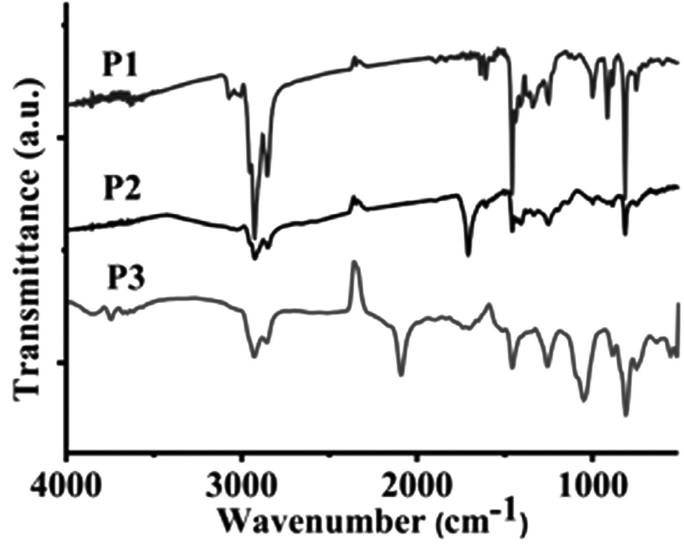

FIGURE 1 FT-IR spectra of the polymers P1, P2, and P3.

cence Spectrophotometer. FT-IR spectra were performed with a Bruker Vertex 70 Spectrophotometer. Molecular weights were determined by Algilent GPC 1200 in THF using a calibration curve of polystyrene standards. TA Instruments Q500 thermal gravimetric analysis (TGA) was used to perform the thermogravimetric analysis measurements. Cyclic voltammetric measurements were performed using Gamry PCI4/300 potentiostat-galvanostat in acetonitrile (ACN)-tetrabutylammonium tetrafluoroborate (TBABF) solvent-electrolyte couple containing $2 \%$ borontrifluoro diethylether $\left(\mathrm{BF}_{3}\right.$ $\mathrm{Et}_{2} \mathrm{O}$ ) by volume. For spectroelectrochemical characterizations polymer films were coated on ITO (Delta Tech. 8-12 $\Omega$, $0.7 \times 5 \mathrm{~cm}^{2}$ ) via spray coating. The polymer films were rinsed and switched between neutral and doped states several times to equilibrate its redox behavior in electrolytic solution. In situ spectroelectrochemical studies were performed using Hewlett-Packard 8453 A diode array spectrometer. A $\mathrm{Pt}$ wire was used as a counter electrode, and an Ag wire as a pseudo-reference electrode which was calibrated externally using $5 \mathrm{mM}$ solution of ferrocene/ferrocenium couple in the electrolytic solution. Also, square wave potential method was used to investigate the ability of switching of the polymer film between its neutral and doped state.

\section{RESULT AND DISCUSSIONS}

\section{Synthesis and Characterization of Copolymers}

Polymer P1 was synthesized by the Suzuki coupling of 2,7dibromo-9,9-bis-(propenyl)-9H-fluorene and 9,9-dihexylfluorene-2,7-bis(trimethyleneborate) in 60\% yield (Scheme 1). Copolymer formation was confirmed by ${ }^{1} \mathrm{H}$ NMR (see Supporting Information Fig. S1) and FT-IR measurements. Polymer $\mathbf{P} \mathbf{2}$ was synthesized from $\mathbf{P 1}$ by reacting $\mathbf{P 1}$ with excess thioglycolic acid (Scheme 1). Its ${ }^{1} \mathrm{H}$ NMR spectra in various solvents were recorded but in all spectra the signals of protons were very broad and poorly resolved to be useful. However, FT-IR spectrum of $\mathbf{P 2}$ depicted in Figure 1 together with the spectrum of $\mathbf{P} \mathbf{1}$ for comparison reasons shows the formation of a strong peak at about $1700 \mathrm{~cm}^{-1}$ due to $\mathrm{C}=0$ stretching suggesting the successful conversion of P1-P2. Furthermore, from the sulfur content determined by the elemental analysis we were able to estimate the degree of 


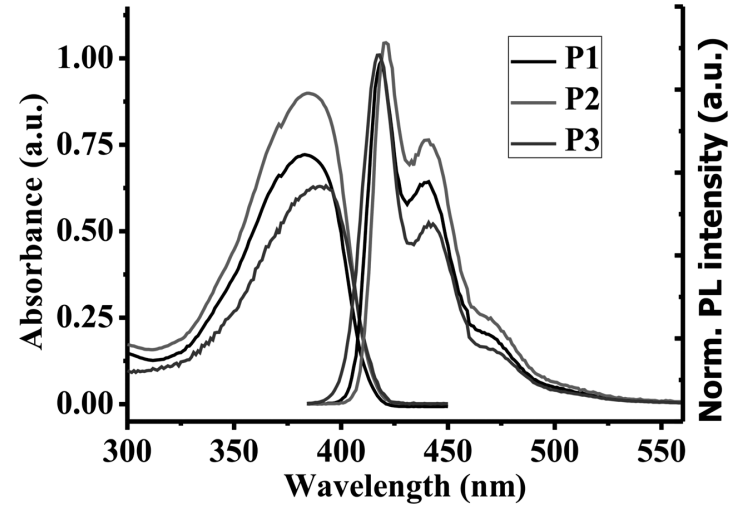

FIGURE 2 UV-vis and PL spectra of the polymer P1 ( $\lambda_{\mathrm{ex}}=384$ $\mathrm{nm}), \mathbf{P 2}\left(\lambda_{\mathrm{ex}}=386 \mathrm{~nm}\right)$, and P3 $\left(\lambda_{\mathrm{ex}}=391 \mathrm{~nm}\right)$.

conversion of allyl side chains through thiol-en reaction as higher than 95\% (see the proposed structure in the experimental part). Water soluble version of P2 (abbreviated as P2S) was synthesized treating $\mathbf{P 2}$ with aqueous $\mathrm{NaOH}$ solution. P3 was synthesized following the literature precedence, ${ }^{33,34}$ in which briefly the precursor copolymer poly[(9,9-dihexylfluorene)-co-alt-(9,9-bis(6-bromohexyl)fluorene)] was treated with sodium azide in DMF (Scheme 1).

The conversion of bromide, in poly[(9,9-dihexylfluorene)-coalt-(9,9-bis(6-bromohexyl)fluorene)], to azide was confirmed by ${ }^{1} \mathrm{H}$ NMR and FT-IR measurements. ${ }^{33,34}$ The upfield-shifted peak of methylene protons adjacent to azide from 3.32 to 3.17 ppm was observed in the ${ }^{1} \mathrm{H}$ NMR spectrum upon the conversion of bromide to azide. The appearance of a new peak at about $2094 \mathrm{~cm}^{-1}$, due to azide stretching, in the FT-IR spectrum of P3 further indicates the conversion of bromide to azide group (Fig. 1). The weight average and number average molecular weights $\left(M_{\mathrm{w}} / M_{\mathrm{n}}\right)$ of $\mathbf{P 1}, \mathbf{P 2}$, and P3 were determined via GPC using polystyrene as standard and were found to be $9.02 \times 10^{3} / 4.01 \times 10^{3}, 12.9 \times 10^{4} / 9.88 \times 10^{3}$, and $2.04 \times 10^{4} / 3.61 \times 10^{3} \mathrm{~g} \mathrm{~mol}^{-1}$ for P1, P2, and P3, respectively. Furthermore, using elemental analysis results, we estimated the number of repeating units of P1 and P2 as 5 and 8, respectively. The proposed structures in accordance with the elemental analysis are shown in the experimental section.

\section{Photophysical Properties}

Optical characterization of three polymers was accomplished by recording their absorption and fluorescence emission spectra in THF and the results are depicted in Figure 2. As seen from Figure 2, all three polymers exhibit an absorption band around $385 \mathrm{~nm}$ due to $\pi \rightarrow \pi^{*}$ transition. Their wavelengths of maximum fluorescence emission are well separated from their absorption edges indicating that self-absorption is negligible (Fig. 2). ${ }^{33}$ The fluorescence quantum yields were calculated as $0.75,0.48$, and 0.86 for P1, P2, and P3, respectively, using quinine sulfate as the standard. The relatively small Stokes shifts (34 nm for P1, $35 \mathrm{~nm}$ for P2 and $26 \mathrm{~nm}$ for $\mathbf{P} 3 \mathrm{~nm}$ ) between the absorption and emission maximum wavelengths of the polymers, P1, P2, and P3 indicate the rigidity of the conjugated polymer backbone which hinders deformation in going from the ground to the excited state. $^{26}$

\section{Thermal Properties}

Thermal stability of the polymers P1, P2, and P3 were evaluated by TGA under nitrogen gas flow and their TGA curves are illustrated in Figure 3. Polymer P1 displays a main decomposition at $455{ }^{\circ} \mathrm{C}$ due to the scission of alkly side chains from the polymer backbone [Fig. 3(a)]. Conversely, TGA profile of P2 shows that decomposition occurs in several steps, in which the first step involves the decomposition of carboxyl groups of side chains by the release of carbon dioxide with a weight loss of $12 \%$ and the second step is associated with the scission of alkyl chains [Fig. 3(b)]. TGA thermograph of P3 clearly indicates that the thermal degradation of P3 takes place in more than one step [Fig. 3(c)]. In the first step, azide groups of the side chains are decomposed at around $223{ }^{\circ} \mathrm{C}$ as reported previously ${ }^{33,34}$ and the subsequent steps at 354 and $453{ }^{\circ} \mathrm{C}$ involve the scission of alkyl chains from the fluorene backbone. These results indicate that although all three polymers are thermally stable, P1 exhibits higher thermal stability than the polymers P2 and P3.

\section{Electrochemical and Electro-0ptical Properties}

To elucidate the electrochemical properties of the polymers, polymers were deposited on an ITO electrode via spray coating from their THF solutions $(6.0 \mathrm{mg} / 1.0 \mathrm{~mL}$ THF). Cyclic voltammograms were recorded in $0.1 \mathrm{M}$ TBABF solution in ACN containing $\mathrm{BF}_{3}-\mathrm{Et}_{2} \mathrm{O}$ ( $2 \%$ by volume) and the resulting voltammograms are shown in Figure 4. The polymer films exhibited a pseudo-reversible redox couple $\left(E_{\mathrm{p}, \mathrm{a}}=1.22 \mathrm{~V}\right.$ and $E_{\mathrm{p}, \mathrm{c}}=0.96 \mathrm{~V}$ for P1, $E_{\mathrm{p}, \mathrm{a}}=1.07 \mathrm{~V}$, and $E_{\mathrm{p}, \mathrm{c}}=0.97 \mathrm{~V}$ for P2 and $E_{\mathrm{p}, \mathrm{a}}=1.16 \mathrm{~V}$ and $E_{\mathrm{p}, \mathrm{c}}=0.94 \mathrm{~V}$ for P3) due to (a)

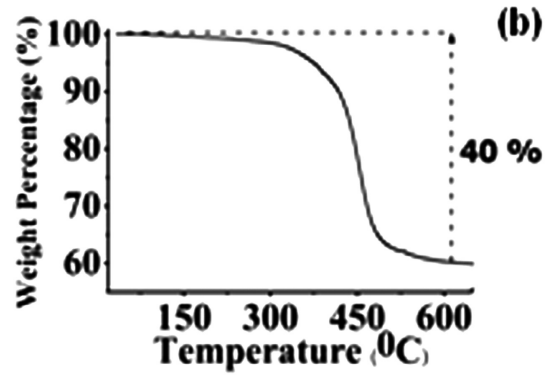

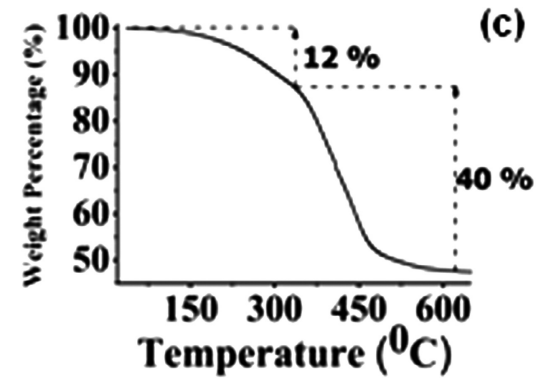

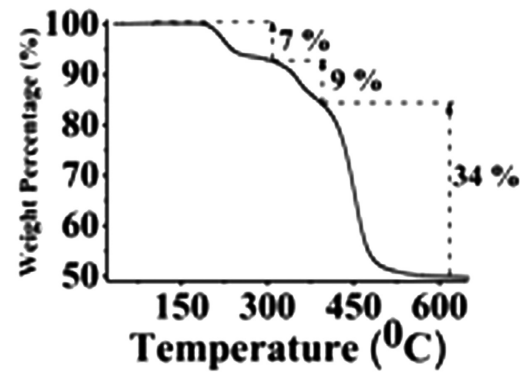

FIGURE 3 Thermogravimetric analysis of (a) P1, (b) P2, and (c) P3 under nitrogen atmosphere at a heating rate of $20{ }^{\circ}$ C/min. 

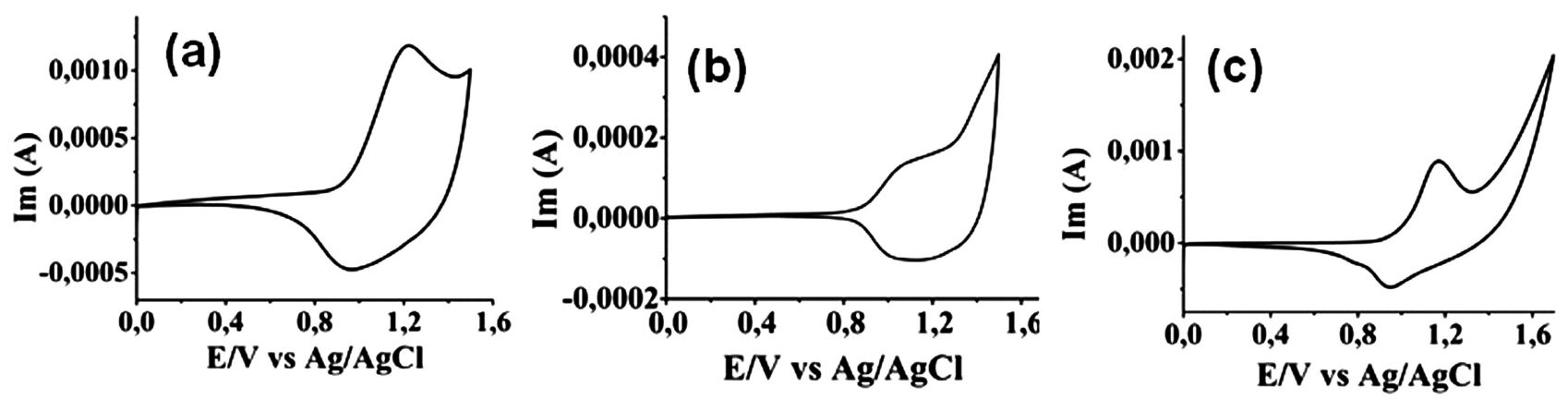

FIGURE 4 Cyclic voltammograms of (a) P1, (b) P2, and (c) P3 spray coated on ITO at $100 \mathrm{mV} \mathrm{s}^{-1}$ in $0.1 \mathrm{M}$ TBABF/ACN.

doping and de-doping with a half peak potential of 1.07, 0.97, and $1.07 \mathrm{~V}$ for P1, P2, and P3, respectively. These very close $E_{\mathrm{p}, \mathrm{a}}$ values of the three polymers indicate that different side groups on the repeating unit have negligible effect on the doping process.

Electro-optical properties of the polymer films on ITO were elaborated by recording the changes in the absorption spectra under a variety of voltage pulses after neutralization at $0.0 \mathrm{~V}$. The electronic absorption spectra of neutral forms of the films exhibit an absorption band at around 382, 392, and $388 \mathrm{~nm}$ for $\mathbf{P 1}, \mathbf{P 2}$, and $\mathbf{P 3}$, respectively. These bands are due to $\pi-\pi^{*}$ transition and they all lose intensity during oxidation which is accompanied by the appearance of new intensifying bands. In the case of P2 (Fig. 5), as the valanceconduction band at $392 \mathrm{~nm}$ diminishes a new band starts to intensify at about $540 \mathrm{~nm}$ in the potential range of $0.0-1.20$ $\mathrm{V}$. Upon further oxidation up to $1.30 \mathrm{~V}$, a new broad band beyond $900 \mathrm{~nm}$ also starts intensifying. Appearance of these new bands indicates the formation of charge carriers. All spectra recorded during potential cycling between 0.0 and $1.30 \mathrm{~V}$ passes through a clear isosbestic points at $443 \mathrm{~nm}$, indicating that polymer film was being interconverted between its neutral and oxidized states. The changes in the electronic absorption spectra of $\mathbf{P 2}$ film is also accompanied by a color change, transparent to violet, indicating that P2 film exhibits electrochromic behavior. In the case of P1 [Supporting Information Fig. S2(a)], the new band due to the formation of charge carriers appears at about $560 \mathrm{~nm}$ accompanied with an electrochromic response (transparent in the neutral state and violet in the oxidized state). Similar spectroelectrochemical changes were also observed for P3 during potential scanning from 0.0 to $1.45 \mathrm{~V}$ [see Supporting Information Fig. S2(b)].

The band gap $\left(E_{\mathrm{g}}\right)$ values of polymer films deposited on ITO electrodes via spray coating determined from the commencement of low energy end of $\pi-\pi^{*}$ transitions (i.e., 382, 392, and $388 \mathrm{~nm}$ for $\mathbf{P 1}, \mathbf{P 2}$, and $\mathbf{P 3}$, respectively), utilizing spectroelectrochemical data. It was found that $E_{\mathrm{g}}$ values are very close to each other being in the range of $2.80-2.90 \mathrm{eV}$ (Table 1).

Electrochemical and Optical Stability of Polymer Films As one of the important characteristics of an electrochromic material is its electrochemical/optical stability upon multiple switching in a short response time, ${ }^{35}$ these parameters for the films, P1, P2, and P3 were investigated under a rectangular wave input of $0.0 \mathrm{~V}$ (residence time $2 \mathrm{~s}$ ) to $1.15 \mathrm{~V}$ (residence time $3 \mathrm{~s}$ ) for $\mathbf{P 1}, 0.0 \mathrm{~V}$ (residence time $1 \mathrm{~s}$ ) to $1.25 \mathrm{~V}$ (residence time $2 \mathrm{~s}$ ) for $\mathbf{P} 2$ and $\mathbf{P} 3$ by monitoring the visible transmittance at $560 \mathrm{~nm}$ for P1 and P3, at $540 \mathrm{~nm}$ for P2 and the results are shown in Figure 6 for P2 and Supporting Information Figure S3 for P1 and P3. To evaluate the electrochemical stability, cyclic voltammograms after each 100 switch were recorded with the scan rate of $200 \mathrm{mV} / \mathrm{s}$. Although P1 showed good electrochemical stability (only $12 \%$ loss in electroactivity after 600 cycle), P2 and P3 exhibited lower stability. The reason for the lower stability was thought to be due to the presence of polar pendant groups which makes them slightly soluble in ACN. Thus, to make them stable, they were crosslinked via thermal treatment. P2 was administrated to $90{ }^{\circ} \mathrm{C}$ for $2 \mathrm{~h}$ in vacuum oven while P3 was encountered to $100{ }^{\circ} \mathrm{C}$ for $5 \mathrm{~h}$ prior to potential pulses and the results are shown in Supporting Information Figure S4. Although, P2 lost $10 \%$ of its electroactivity even after 100 switches, after crosslinking of the polymer film via thermal treatment its stability increased to a great extent and a $21 \%$ loss in the electroactivity was observed after 500 switches. In addition, almost same situation was observed for P3 after crosslinking it retains 14\% its electroactivity after 700 switches.

In our previous publications, we discussed in detail the thermal and the light-triggered cross-linking mechanism of azide

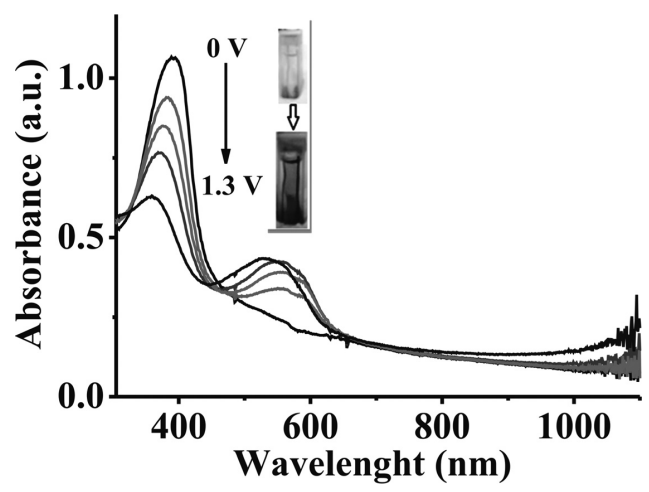

FIGURE 5 Electronic absorption spectra of $\mathbf{P} 2$ in $0.1 \mathrm{M}$ TBABF/ $\mathrm{ACN}$ solution during anodic oxidation of the polymer film. 
TABLE 1 Optical and Electrochemical Properties of Polymers P1, P2, and P3

\begin{tabular}{|c|c|c|c|c|c|c|c|c|}
\hline & \multirow[t]{2}{*}{$\lambda_{\max }(\mathrm{nm})$} & \multirow[t]{2}{*}{$E_{\mathrm{g}}(\mathrm{eV})$} & \multirow[t]{2}{*}{ HOMO (eV) } & \multirow[t]{2}{*}{ LUMO (eV) } & \multicolumn{2}{|c|}{$\begin{array}{l}\text { Switching } \\
\text { Time (s) }\end{array}$} & \multirow[t]{2}{*}{ CE } & \multirow[t]{2}{*}{ Electro-Chemical Stability } \\
\hline & & & & & $t_{\mathrm{ox}}$ & $t_{\text {red }}$ & & \\
\hline P1 & 382 & 2.93 & 5.33 & 2.40 & 1.1 & 1.7 & 145 & $12 \%$ loss after 600 cycle \\
\hline P2 & 392 & 2.80 & 5.27 & 2.47 & 1.0 & 1.6 & 352 & $21 \%$ loss after 500 cycle \\
\hline P3 & 388 & 2.89 & 5.30 & 2.41 & 0.91 & 2.0 & 119 & $14 \%$ loss after 700 cycle \\
\hline
\end{tabular}

containing polymer P1. ${ }^{33-34}$ Briefly, azide groups decompose under light or at certain temperature to generate a reactive nitrene species which can insert in the side chain or the backbone causing intracrosslinking and intercrosslinking of the polymer chains. Conversely, the cross-linking mechanism of the polymer P3 is probably taking place through forming a carboxylic acid anhydride between the polymer side-chains.

It is found that $\mathbf{P 2}$ showed a reversible response between a potential range from $0.0 \mathrm{~V}$ (neutral) to $1.25 \mathrm{~V}$ (oxidized) with a response time of $1.0 \mathrm{~s}$ for oxidation and $1.6 \mathrm{~s}$ for reduction at $95 \%$ of the maximum transmittance and the optical contrast $(\Delta \% T)$ was calculated as $7.01 \%$ at $540 \mathrm{~nm}$ (Fig. 6). Optical contrast values of $20.00 \%$ (540 nm), and 14.80\% (560 nm) were obtained for $\mathbf{P 1}$ and $\mathbf{P 3}$, respectively (Supporting Information Fig. S3).

Coloration efficiency (CE) is a useful term for measuring the power efficiency of the electrochromic devices and can be calculated via optical density using the following equations at a given wavelength ${ }^{36,37}$;

$$
\mathrm{CE}(\lambda)=\Delta \mathrm{OD}(\lambda) / Q_{\mathrm{d}} \text { and } \Delta \mathrm{OD}(\lambda)=\log \left[T_{\mathrm{ox}}(\lambda) / T_{\text {red }}(\lambda)\right]
$$

(where $Q_{\mathrm{d}}$ is the injected/ejected charge during a redox process; $T_{\mathrm{ox}}$ and $T_{\text {red }}$ are the transmittance in the oxidized and the neutral states, respectively).

On the basis of these equations, CE values were found as 145, 119, and $352 \mathrm{~cm}^{2} / \mathrm{C}$ at $540 \mathrm{~nm}$ for P1, P3, and P2, respectively. CE values for all polymer films are also tabulated in Table 1 for comparison reasons. Among the three polymers, $\mathbf{P} 2$ exhibits the highest CE value.
Highest occupied molecular orbital/lowest unoccupied molecular orbital (HOMO/LUMO) energy levels of the polymers were elucidated utilizing their ionization potentials and electron affinities obtained from experimental data. First, the ionization potentials were evaluated using the following empirical relation, eq $1 ;^{38}$

$$
\mathrm{I}_{\mathrm{p}}=\left(E_{\mathrm{ox}}+4.4\right) \mathrm{eV}
$$

The onset of oxidation potentials of P1 (0.93 V vs. Ag wire), P2 (0.87 V vs. Ag wire), and P3 (0.90 V vs. Ag wire) were used as $E_{\mathrm{ox}}$ in eq 1 . Electron affinities were estimated by subtracting the band gap energy from $I_{\mathrm{p}}$ and the results are illustrated in Table 1. From the optical and electrochemical data given in Table 1, we can conclude that the nature of the side chains of polymers has negligible influence on the emission properties and energy levels of the main chain, such as the energy band gap.

\section{Metal Ion Sensing Properties of the Polymers P1, P2, P2S, and P3}

The metal ion sensory abilities of the fluorene-based polymers P1, P2, P2S, and P3 having different functional groups on their side chains (i.e., allyl, carboxylic acid, carboxylate, and azide) were investigated and the results were compared with PF-H carrying no functional groups to understand the extent of the functional group effect on the fluorescent sensing.

The sensing ability of the polymers $\mathbf{P 1}, \mathbf{P 2}, \mathbf{P 3}$, and $\mathbf{P F}-\mathbf{H}$ in THF and P2S in water was investigated by titrating them with a number of different aqueous metal ion solutions including $\mathrm{Fe}^{3+}, \mathrm{Fe}^{2+}, \mathrm{Cu}^{2+}, \mathrm{Ni}^{2+}, \mathrm{Zn}^{2+}, \mathrm{Ag}^{+}, \mathrm{Pb}^{2+}, \mathrm{Cd}^{2+}$, and
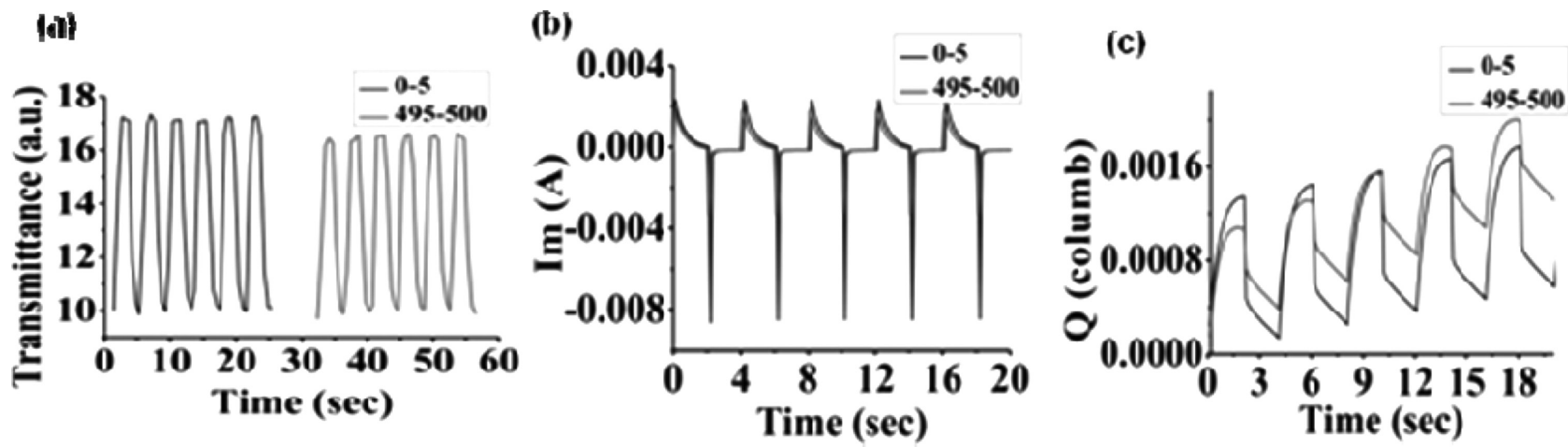

FIGURE 6 (a) Chronoabsorbtometry, (b) current density, and (c) chronocoloumetry experiments for P2 at $\lambda_{\max }(540 \mathrm{~nm})$ under rectangular voltage signal between 0 and $1.25 \mathrm{~V}$. 
(a)
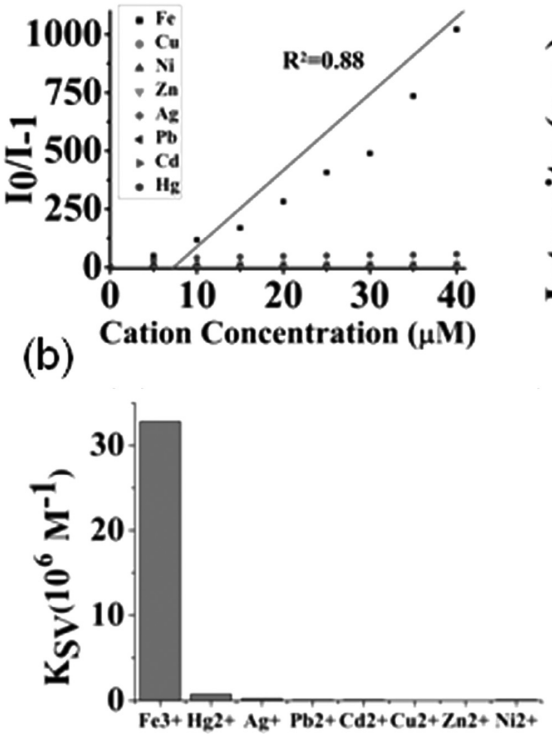

(c) $750-0 \mu \mathrm{M} \mathrm{Fe}^{3+}$

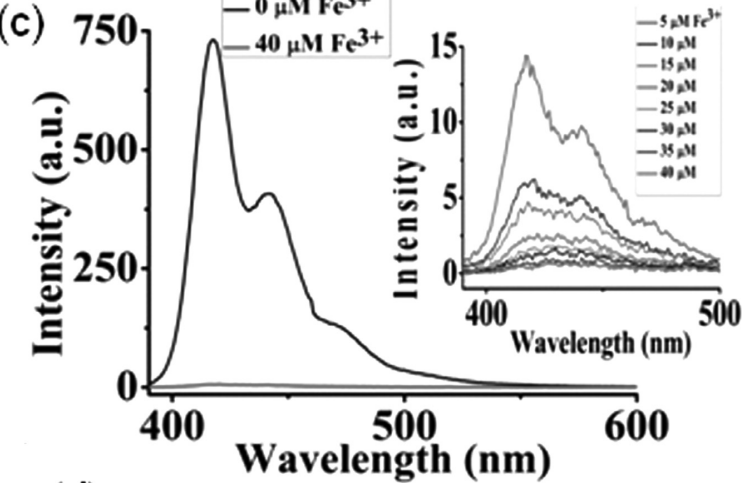

(d) (ii)

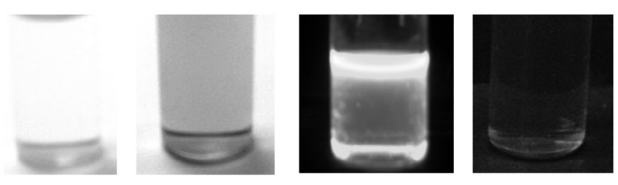

FIGURE 7 (a) The Stern-Volmer plots of $\mathbf{P 2}$ in the presence of various metal ions (each 5-40 $\mu \mathrm{M}$ ). Metal ion solutions were prepared from $\mathrm{Fe}\left(\mathrm{NO}_{3}\right)_{3} \cdot 9 \mathrm{H}_{2} \mathrm{O}, \mathrm{Cu}\left(\mathrm{NO}_{3}\right)_{2} \cdot 3 \mathrm{H}_{2} \mathrm{O}, \mathrm{Ni}\left(\mathrm{NO}_{3}\right)_{2} \cdot 6 \mathrm{H}_{2} \mathrm{O}, \mathrm{Zn}\left(\mathrm{NO}_{3}\right)_{2} \cdot 6 \mathrm{H}_{2} \mathrm{O}, \mathrm{AgNO}_{3}, \mathrm{Hg}\left(\mathrm{NO}_{3}\right)_{2}, \mathrm{~Pb}\left(\mathrm{NO}_{3}\right)_{2}, \mathrm{Cd}\left(\mathrm{NO}_{3}\right)_{2} \cdot 4 \mathrm{H}_{2} \mathrm{O}$ in THF, $(\mathrm{b})$ $K_{\text {sv }}$ values, (c) the fluorescence emission spectra of $\mathbf{P 2}\left(5.0 \times 10^{-6} \mathrm{~mol} \mathrm{~L}^{-1}\right.$ in THF, with respect to the repeat unit) with successive addition of 5-40 $\mu \mathrm{M} \mathrm{Fe}{ }^{3+}$ aqueous solution, and (d) photographs of P2 solution in THF in the absence ( $i$ and iii) and the presence of $\mathrm{Fe}^{3+}$ ions (ii and iv) in daylight ( $\mathrm{i}$ and ii) under handheld UV light (iii and iv).

$\mathrm{Hg}^{2+}$ at desired concentrations and subsequently monitoring the changes in their emission spectra at room temperature $\left(\lambda_{\text {exc }}=380 \mathrm{~nm}\right)$. Binding affinities of these polymers against the aforementioned metal ions $\left(\mathrm{Fe}^{2+}\right.$ not shown here) are given in the form of Stern-Volmer plot in Figures 7 and 8 for P2 and P2S, respectively (see also Supporting Information Fig. S5 for other polymers and Supporting Information Fig. S8 for the binding affinity of $\mathrm{Fe}^{2+}$ with P2).

All of these polymers appear to have a higher selectivity toward $\mathrm{Fe}^{3+}$ ions than the others, albeit at a different degree. The effect of water addition into THF solution of polymers that might cause possible changes in the optical properties of polymers due to conformational changes was also taken into account. Similar volumes of water used in the addition of metal ion solutions were added into THF solution of polymers. Their absorption and emission spectra were recorded but no changes were observed in their wavelengths and intensities (Supporting Information Fig. S6 shows the effect of water addition to P2) indicating that the water effect is negligible for a given concentration.

Their quenching efficiencies against $\mathrm{Fe}^{3+}$ ions were plotted and illustrated in Figure 9 for comparison. The Stern-Volmer constants of $\left(K_{\mathrm{sv}}\right)$ were calculated as $4.41 \times 10^{6} \mathrm{M}^{-1}, 3.28$ $\times 10^{7} \mathrm{M}^{-1}, 1.25 \times 10^{6} \mathrm{M}^{-1}, 6.56 \times 10^{6} \mathrm{M}^{-1}$, and $5.88 \times$ $10^{6} \mathrm{M}^{-1}$ for P1, P2, P2S, P3, and PF-H, respectively. As can be seen, $K_{\mathrm{sv}}$ value of $\mathbf{P} 2$ is almost fivefolds greater than those of P1, P3, PF-H, and 25-folds greater than that of P2S. Relatively small $K_{\mathrm{sv}}$ value for $\mathbf{P} 2-\mathbf{S}$ can be attributed to its low fluorescent quantum yield (around 10\%) as well as a solvent effect because the measurements were taken in aqueous solution. However, its $K_{\mathrm{sv}}$ value is still quite high to sense $\mathrm{Fe}^{3+}$ ions in aqueous solution and this feature is highly desirable in the design of biological sensors. Moreover, the absorption maxima of P1, P2, and P3 at 384, 396, and 391, respectively, showed around a $8 \mathrm{~nm}$ red-shift upon titrating with $\mathrm{Fe}^{3+}$ (Supporting Information Fig. S7) but no changes were observed by the addition of other aforementioned metal ions including $\mathrm{Fe}^{2+}$ (Supporting Information Fig. S8).

Although all polymers possess a similar fluorene backbone, different groups and functionalities were attached to their ninth position. The results indicate that even PF-H which does not contain any functional groups but carrying only alkyl chains as a side group, exhibits a high fluorescent quenching efficiency toward $\mathrm{Fe}^{3+}$ ions suggesting that fluorene backbone binds with $\mathrm{Fe}^{3+}$ ions probably forming a ferrocene-like complex. In the case of $\mathbf{P} 2$, the presence of fluorene backbone as well as carboxylic groups which can bind with $\mathrm{Fe}^{3+}$ ions causes a very efficient energy transfer and in turn, this quenches the fluorescent emission.

Although the addition of $\mathrm{Ag}+, \mathrm{Pb}^{2+}, \mathrm{Cd}^{2+}, \mathrm{Cu}^{2+}, \mathrm{Zn}^{2+}, \mathrm{Ni}^{2+}$, and $\mathrm{Fe}^{2+}$ ions to the polymer solutions has resulted only a negligible quenching, as shown in Figure 7(a), P2 displayed a small affinity for $\mathrm{Hg}^{+2}$ ion resulting with the possibility of interference by those two ions. To check the reliability of this possibility, the fluorescence spectrum of P2, after addition of $\mathrm{Fe}^{+3}$ and further addition of $\mathrm{Hg}^{+2}$ was recorded. As shown in the Supporting Information Figure S9, addition of $\mathrm{Hg}^{+2}$ did not result in further decrease of fluorescence intensity. 
(a)

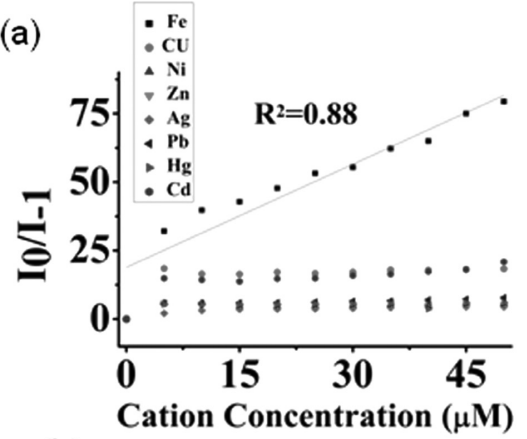

(b)

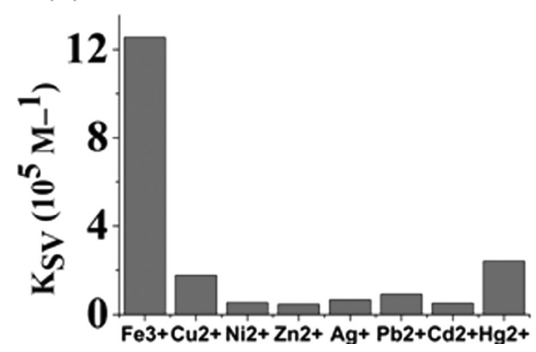

(c)

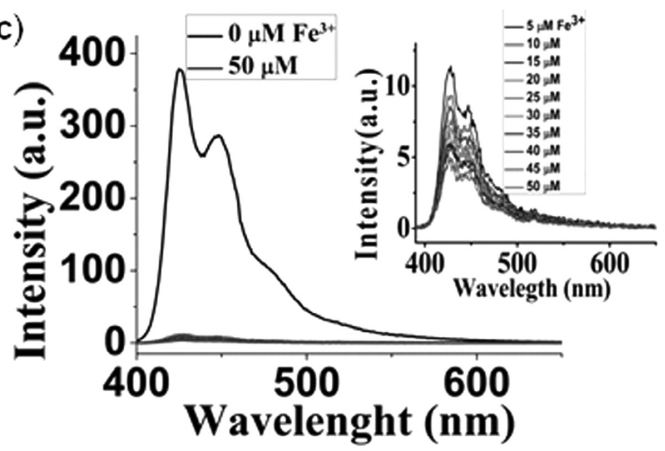

(d) (ii)

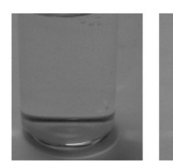

(iii)

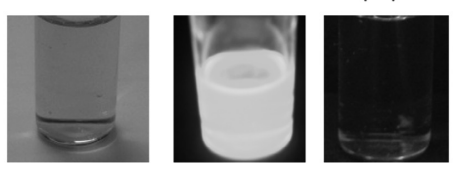

(iv)

FIGURE 8 (a) The Stern-Volmer plots of P2S in the presence of various metal ions (each 5-50 $\mu \mathrm{M}$ ). Metal ion solutions were prepared from $\mathrm{Fe}\left(\mathrm{NO}_{3}\right)_{3} \cdot 9 \mathrm{H}_{2} \mathrm{O}, \mathrm{Cu}\left(\mathrm{NO}_{3}\right)_{2} \cdot 3 \mathrm{H}_{2} \mathrm{O}, \mathrm{Ni}\left(\mathrm{NO}_{3}\right)_{2} \cdot 6 \mathrm{H}_{2} \mathrm{O}, \mathrm{Zn}\left(\mathrm{NO}_{3}\right)_{2} \cdot 6 \mathrm{H}_{2} \mathrm{O}, \mathrm{AgNO} \mathrm{Hg}_{3}\left(\mathrm{NO}_{3}\right)_{2}, \mathrm{~Pb}\left(\mathrm{NO}_{3}\right)_{2}, \mathrm{Cd}\left(\mathrm{NO}_{3}\right)_{2} \cdot 4 \mathrm{H}_{2} \mathrm{O}$ in THF, (b) $K_{\mathrm{sv}}$ values, and (c). the fluorescence emission spectra of P2S $\left(5.0 \times 10^{-5} \mathrm{~mol} \mathrm{~L}^{-1}\right.$ in water) with successive addition of 5-50 $\mu \mathrm{M}$ $\mathrm{Fe}^{3+}$ aqueous solution, (d) photographs of aqueous solution of P2-S in the absence (i and iii) and the presence of $\mathrm{Fe}^{3+}$ ions (ii and iv) in daylight (i and ii) under handheld UV light (iii and iv).

\section{CONCLUSIONS}

In this work, a series of novel, solvent processable, fluorenebased conjugated copolymers were synthesized, characterized and their thermal, optical, electrochemical, and sensory properties were investigated. The polymers were deposited on an ITO electrode by spray coating and the electrochemical properties of the resulting thin films were investigated using CV. The polymer films exhibited a pseudo-reversible redox and electrochromic behaviors; transparent in the neutral state and dark violet in the oxidized state. Among three polymers, $\mathbf{P} 2$ possesses the shortest response time and the highest $C E$ value $\left(352 \mathrm{~cm}^{2} / \mathrm{C}\right.$ at $\left.540 \mathrm{~nm}\right)$. These polymers emit blue light (emission wavelength at $440 \mathrm{~nm}$ in THF) with high fluorescent quantum yields and have a band gap value around $2.9 \mathrm{eV}$. It was also demonstrated that these polymers were able to detect $\mathrm{Fe}^{3+}$ ions in THF (P1, P2, and P3) and in aqueous solution (P2S). The results indicate that even PF-

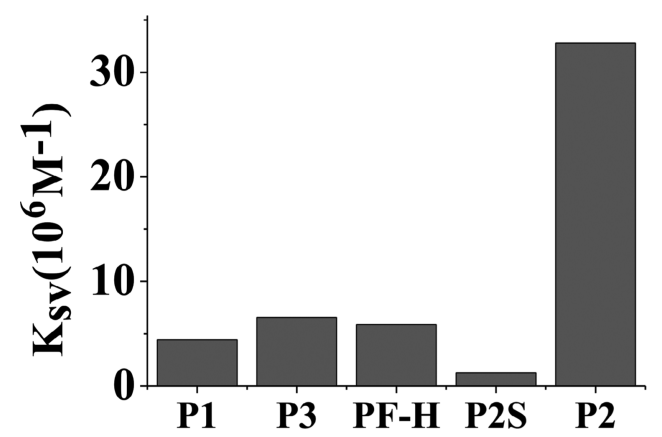

FIGURE $9 K_{\mathrm{sv}}$ values of PF-H, P1, P2, P2S, and P3.
H which does not contain any functional groups but carrying only alkyl chains as a side group, exhibits a high fluorescent quenching efficiency toward $\mathrm{Fe}^{3+}$ ions suggesting that fluorene backbone binds with $\mathrm{Fe}^{3+}$ ions probably forming a ferrocene-like complex. However, among them P2 has the highest $K_{\mathrm{sv}}$ value $\left(3.28 \times 10^{7} \mathrm{M}^{-1}\right)$ which is almost fivefolds greater than those of P1, P3, and PF-H because it contains thioglycolic acid side chains as well as fluorene backbone. This value is also higher than the one reported in the literature $\left(2.24 \times 10^{6} \mathrm{M}^{-1}\right)$, in which $\mathrm{Fe}^{3+}$ was detected in the solution of phosphonate containing $\mathrm{PF}$ in $\mathrm{CH}_{2} \mathrm{Cl}_{2} \cdot{ }^{29}$ Thus, $\mathrm{Fe}^{3+}$ ions can form complex with thioglycolic acid groups through electrostatic interaction and this further causes a decrease in fluorescent emission. As the results indicate, P2 is a promising candidate as a metal ion sensor with a remarkably high fluorescent quenching efficiency and an ability to detect $\mathrm{Fe}^{3+}$ ions selectively in organic solvents as well as in aqueous solutions when it is converted to its salt. The later feature is particularly important for biological sensor applications.

\section{ACKNOWLEDGMENTS}

This work was supported by TUBITAK-TBAG 210 T139.

\section{REFERENCES AND NOTES}

1 M. Berggren, G. Gustafsson, O. Inganäs, M. R. Andersson, O. Wennerström, T. Hjertberg, Adv. Mater. 1994, 6, 488-490.

2 A. Gadisa, E. Perzon, M. R. Andersson, O. Inganäs, Appl. Phys. Lett. 2007, 90, 113510. 
3 J. H. Burroughes, D. D. C. Bradley, A. R. Brown, R. N. Marks, K. Mackay, R. H. Friend, P. L. Burns, A. B. Holmes, Nature 1990, 347, 539-541.

4 S. E. Shaheen, C. J. Brabec, N. S. Sariciftci, F. Padinger, T. Fromherz, J. C. Hummelen, Appl. Phys. Lett. 2001, 78, 841-843.

5 F. Zhang, W. Mammo, L. M. Andersson, S. Admassie, M. R. Andersson, O. Inganäs, Adv. Mater. 2006, 18, 2169-2173.

6 I. Schwendeman, R. Hickman, G. Sonmez, P. Schottland, K. Zong, D. Welsh, J. R. Reynolds, Chem. Mater. 2002, 14, 3118-3122.

7 H. Meng, D. Tucker, S. Chaffins, Y. Chen, R. Helgeson, B. Dunn, F. Wudl, Adv. Mater., 2003, 15, 146-149.

8 D. T. McQuade, A. E. Pullen, T. M. Swager, Chem. Rev. 2000, 100, 2537-2574.

9 S. J. Dwight, B. S. Gaylord, J. W. Hong, G. C. Bazan, J. Am. Chem. Soc. 2004, 126, 16850-16859.

10 S. W. Thomas, III, G. D. Joly, T. M. Swager, Chem. Rev. 2007, 107, 1339-1386.

11 F. I. Wu, P. I. Shih, C. F. Shu, Y. L. Tung, Y. Chi, Macromolecules 2005, 38, 9028-9036.

12 Y. Yang, Q. Pei, J. Appl. Phys. 1997, 81, 3294-3298.

13 B. Liu, W. L. Yu, Y. H. Lai, W. Huang, Chem. Mater. 2001, 13, 1984-1991.

14 G. Nie, T. Cai, L. Qu, J. Xu, Q. Wei, S. Zhang, J. Electroanal. Chem. 2008, 612, 191-200.

15 G. R. Klaerner, D. Miller, Macromolecules 1998, 31, 2007-2009.

$16 \mathrm{~J}$. Rault-Berthelot, E. Raoult, F. LeFloch, J. Electroanal. Chem. 2003, 546, 29-34.

17 G. Klarner, M. H. Davey, W. D. Chen, J. C. Scott, R. D. Miller, Adv. Mater. 1998, 10, 993-997.

18 A. Charas, J. Morgado, J. M. G. Martinho, L. Alcácer, F. Cacialli, Chem. Commun. 2001, 13, 1216-1217.

19 B. Liu, Y. Niu, W. Yu, Y. Cao, W. Huang, Synth. Metals 2002, 129, 129-134.

20 J. Lee, D. Hwang, H. Park, L. Do, H. Y. Chu, T. Zyung, R. D. Miller, Synth. Metals 2000, 111, 195-197.
21 B. Bezgin, A. M. Önal, Electrochim. Acta 2010, 55, 779-784.

22 P. Sonar, J. Zhang, A. C. Grimsdale, K. Mullen, M. Surin, R. Lazzaroni, P. Leclere, S. Tierney, M. Heeney, I. McCulloch, Macromolecules 2004, 37, 709-715.

23 J. Yang, C. Jiang, Y. Zhang, R. Yang, W. Yang, Q. Hou, Y. Cao, Macromolecules 2004, 37, 1211-1218.

24 S. P. Liu, H. S. O. Chan, S. C. Ng, J. Polym. Sci. Part A: Polym. Chem. 2004, 42, 4792-4801.

25 B. B. Carbas, A. Kivrak, A. M. Önal, Electrochim. Acta 2011, 58, 223-230.

26 B. Liu, W.-L. Yu, J. Pei, S. Y. Liu, Y. H. Lai, W. Huang, Macromolecules 2001, 34, 7932-7940.

27 C. Oin, X. Wu, B. Gao, H. Tong, L. Wang, Macromolecules 2009, 42, 5427-5429.

28 Z. Li, X. Lou, H. Yu, Z. Li, J. Qin, Macromolecules 2008, 41, 7433-7439.

29 G. Zhou, G. Qian, L. Ma, Y. Cheng, Z. Xie, L. Wang, X. Jing, F. Wang, Macromolecules 2005, 38, 5416-5424.

30 C. Oin, Y. Cheng, L. Wang, X. Jing, L. Wang, Macromolecules 2008, 41, 7798-7804.

31 A. T. Dwivedi, G. Saikia, P. K. lyer, J. Mater. Chem., 2011, 21, 2502-2507.

32 C. Qin, X. Wu, H. Tong, L. Wang, J. Mater. Chem., 2010, 20, 7957-7964.

33 I. O. Huyal, U. Koldemir, T. Ozel, H. V. Demir, D. Tuncel, J. Mater. Chem. 2008, 18, 3568-3574.

34 I. O. Huyal, T. Ozel, U. Koldemir, S. Nizamoglu, D. Tuncel, H. V. Demir, Opt. Exp. 2008, 16, 1115-1124.

35 P. M. S. Monk, R. J. Mortimer, D. R. Rosseinsky, Electrochromism: Fundamentals and Applications; John Wiley \& Sons: Weinheim, 1995.

36 C. L. Gaupp, D. M. Welsh, R. D. Rauh, J. R. Reynolds, Chem. Mater. 2002, 14, 3964-3971.

37 B. D. Reeves, C. R. G. Grenier, A. A. Argun, A. Cirpan, T. D. Mccarley, J. R. Reynolds, Macromolecules 2004, 37, 7559-7569.

38 F. Dierschke, A. C. Grimsdale, K. Müllen, Macromol. Chem. Phys. 2004, 205, 1147-1154. 